\title{
Prevalence of Emerging Protozoa among Crustaceans
}

\author{
Safaa Mohamed M. Essa*
}

\begin{abstract}
Today people are turning to fish as a healthy alternative to red meat. It supplies various essential protein, vitamins, Omega 3 and minerals. It is favored by all people for its delicious taste specially Shrimps and Crabs. However, crustaceans can serve as sources of parasitic infection to man. So this study was planned to estimate prevalence of emerging protozoa among crustaceans. A total of 60 shrimp \& crab samples (30 of each) were collected from different markets in Alexandria Governorate. The intestinal contents of each were milked out. Smears were stained with: a) Quick-hot Gram-Chromotrope staining technique (QHG), b) Kinyoun's acid-fast stain (KAF). Microsporidia was encountered in the whole sample of Shrimps and Crabs by both stains (QHG, KAF). In Shrimps; Cyclospora was defected 40\% followed by Cryptosporidia (33.3\%) by using QHG stain while the results revealed by Kinyoun's acid fast stain were $(40 \%, 80 \%)$ respectively. In Crabs; Cryptosporidia was the second encountered protozoa $53.3 \%$, followed by Cyclospora $33.3 \%$ as demonstrated by QHG. However, Kinyon's acid fast stain showed $86.7 \%, 33.3 \%$ respectively. The least protozoan parasites shown in the present study were Blastocystis hominis 6.7\%, and Dientamoeba fragilis 3.3\%, either by QHG or KAF demonstration.
\end{abstract}

\section{INTRODUCTION}

Fish is important food stuff allover the world due to its high nutritional value as it supplies various essential proteins, vitamins and minerals. Its delicious taste is accepted by people from different nations and of different ages. Food habits vary among people and are influenced by culture norms ${ }^{(1,2)}$. Egypt is rich with different types of salt and fresh water fish which are present in the Mediterranean sea and the River Nile. Fish is considered an essential food resource at the nutritional and economic levels. However the presence of parasites in the consumed fish can materially reduce its commercial value, as well as, be a threat to human health especially in regions where fish are consumed raw, under cooked, or inadequately salted (2). Crustaceans-borne

\footnotetext{
*Lecturer of Parasitology and Medical Entomology. Tropical Health Department.
} 
parasitic diseases tend to go unnoticed and hence under recorded, because the symptoms are often quite general, so, may be mistaken with a range of other infectious diseases. Although there are many helminthic and protozoan parasites that infect fish, some of them are infective to $\operatorname{man}^{(3)}$. Emerging protozoa transmitted by fish and crustaceans are a group of single-celled, obligate intracellular $\operatorname{protozoa}^{(4)}$.

The infective stage of Microsporidia species is the spore. It can survive outside the host cell and reaches the new host through ingestion, inhalation, or via the rectal route. So infected fish is a possible source of human infection. Poorly cooked infected fish may have a role in pleistophora infection in human which have now been described. The infective sporoplasm is induced through the polar tubule into the host cell. The organs mainly affected in human microsporidiosis are the small intestine, the kidney, lower air ways, biliary tracts and skeletal muscles. Although Microsporidia infection in immunocompetent individuals tend to be subclinical in most cases and clinical resolution occurs after a few weeks, immunocompromised patients show overwhelming disease which may lead to death(5).

Current methods to detect Microsporidia are not very sensitive and consistent recoveries are obtained only when the concentration of Microsporidia is 1000 spores/g of feces or higher ${ }^{(6,7)}$. Kahler et al, $2007^{(8)}$ reported that sensitive recovery of Microsporidia was achieved when samples were subjected to DNA extraction using Qiagen Kit, PCR using generic primers for Microsporidia and DNA sequence analysis to identify species.

Cryptosporidiosis is a zoonotic disease, that is well recognized in humans, particularly in immunocompromised persons ${ }^{(5)}$. Many risk factors play a role in the transmission of the disease e.g. 
deficient immunity, zoonotic contact, poor sanitary conditions ...etc. Two spp. of cryptosporidium have been found in fish, $C$. masoris, C. molnari(9).

Oocysts of Cryptosporidia. spp. sporulate within the host and are directly infective when released in faeces of man, birds, cattle, rodents, fish and reptiles. Human cryptosporidiosis is clinically characterized by voluminous watery diarrhea, cramping, abdominal pain, weight loss, nausea, vomiting, low grade fever and headache. Oocyst shedding lasts 3-15 days and can remain for more than a week after the symptoms have ceased, resulting in higher potential for infecting new hosts. The life threatening conditions develop when a large area of the gastrointestinal tract is involved where the parasite can be isolated from ectopic sites e.g., respiratory tract and biliary tree. ${ }^{(10)}$

Myxospora are a group of uncommon protozoa that inhabit a variety of fish tissues, amphibians and reptiles. They belong to phylum Myxozoa causing fish whirling disease. There are speculations that they can cause gastrointestinal disease in immunocompromized individuals. $^{(11)}$

Worldwide, the number of people at risk of parasitic infection, including those in developed countries, is more than half a billion(12). Global sourcing of food, coupled with changing consumer vogues, including the consumption of raw and undercooked fish to retain the natural taste and preserve heat labile nutrients, can increase the risk of disease transmission(13).

In Egypt, several studies were carried out on fish and aquatic animals to identify parasites of medical importance. Recently crustaceans and bivalves proved to harbor protozoa as Microsporidia and Cryptosporidia; all may have great impact on human health ${ }^{(14,15)}$.

Being a coastal city, Alexandria has several fish markets that are visited by a large number of the population, who 
consider fish a favourable meal. We have chosen crab and shrimp in the present work to study the parasites they harbored and try to minimize any threats to human health.

The objective of the present study was to determine prevalence of emerging protozoa that are infesting crustaceans brought from different markets in Alexandria.

\section{Materials and Methods}

\section{Study setting and design}

A comparative study was carried out over a total of 60 shrimp \& crab samples (30 of each) were collected(16). Each specimen of crab was represented by 2 crabs while few shrimps were used as one specimen. The samples were transported to the laboratory with minimum delay, from El-Halaka, ElHadara, Cleopatra and Shidia markets in Alexandria Governorate.

\section{Procedure}

Each specimen was dissected, the intestine was separated, and the intestinal contents were milked out in saline. The fluid was centrifuged at $5000 \mathrm{xg}$ for ten minutes ${ }^{(17,18)}$. Smears from the sediment were prepared and stained with QHG stain $^{(19,20)}$, and KAF stain ${ }^{(21)}$. Examination was done microscopically under oilimmersion lens (X100), the protozoa were counted per 10 fields and the mean was calculated.

\section{Statistical analysis}

The data were statistically analyzed using SPSS version 15 . Intensity of infection of crustaceans with emerging protozoa was assessed by computing means \& standard errors for the number of parasites detected per field of microscopy. The difference recognized between shrimp \& crab infection and the difference between QHG \& KAF stain were compared by Chi square test for qualitative data and Mann Whitney test for quantitative abnormally distributed data. Kolmogorov-Smirnov (K-S) was used to determine normal distribution. Fisher Exact test (FEp) was used in case of small 
frequencies. Level of significance was determined at $\mathrm{P}<0.05$.

\section{Results}

Microsporidia in shrimp ranged from 1-15 with a mean value 6.47 by QHG stain, while as by Kinyoun's acid fast stain it ranged from (5-30) with a mean value 14.97. While in crab it ranged from $10-70$ with a mean value 28.47 by QHG stain, on the other hand it ranged from (5-90) with mean value 27.67 by KAF stain.

It was declared that the density of Microsporidia / field in crab: higher than that in shrimp. The difference was statistically significant in case of QHG stain, table (1).

Data in table (2) illustrated that Cryptosporidia detected in Shrimp \& Crab ranged from 0-3 and 0-2 with a mean value of 0.53 and 0.73 respectively by QHG stain. While by KAF stain it ranged from 0 to10 and (0-3) with mean value 2.0 and 1.6 respectively.
A statistically significant difference was observed in the intensity of infection by Microsporidia in crabs than shrimps by using QHG stain. So Kinyoun's acid fast was better than QHG stain in detection of Cryptosporidia, as the difference was statistically significant, table $(1,2)$.

QHG stain in shrimp revealed that Cyclospora ranged from (0-3) with mean value 0.80 . In crab it ranged from 0 to 1 with mean value 0.33 . On the other hand using KAF stain, it showed a range $0-1$ and (0-3) with mean value $0.40,0.47$ in shrimp $\&$ crab respectively, Table (3).

Results given in Table (4) declared that Microsporidia were present in the whole sample of shrimp using both stains QHG \& KAF. A statically significant difference between the percentages of other emerging protozoa which were $33.3 \%$ by QHG stain and $80 \%$ by KAF stain for Cryptosporidia. While Cyclospora percentage was the same $(40 \%)$ by both stains. 
Regarding crab the whole sample showed Microsporidia using both stains. Cryptosporidia was detected in more than half of the sample (53.3\%) by QHG stain and $86.7 \%$ by KAF stain. This difference was statistically significant. Cyclospora percentage was constant by both stains (33.3\%), table (5).

Blastocystis hominis and Dientamoeba fragilis were the least protozoan parasites encountered in Shrimp and crab. Blastocystis hominis was $6.7 \%$ by both stains. Lastly Dientamoeba fragilis (3.3\%) in both shrimp and crab by KAF stain only.

Table (6) showed the difference between different markets as regard intensity of microsporidial infection in shrimp and crab. It was clear that Halaka and Cleopatra samples were the least harboring parasites either by QHG or KAF stain in both shrimp \& crab, followed by Shidia, then Hadara. The difference between Halaka \& Shidia or Hadra markets was statistically significant.

\section{Discussion}

Water, soil and food are important environmental routes for transmission of many protozoan parasites. The increased demand, global sourcing and rapid transport of foods, besides, consumers habits of inadequate cooking, all contribute to increase risk of food-borne zoonotic diseases $^{(13)}$.

With the growing awareness of providing food for the increasing population, in recent years more attention has been directed to the utilization of salt and fresh water fish ${ }^{(2)}$. Sea food (shrimp \& crab) has traditionally been a popular part of the diet in many parts of the world and in some countries it constitutes the main supply of animal protein. Today, even more people are turning to fish as a healthy alternative to red meat ${ }^{(3)}$.

In Alexandria, people have a strong tradition of eating fish, which is considered a tasty dish commonly consumed by 
inhabitants and visitors of Alexandria, especially in the summer season.

In the present work, examination of the intestinal contents of the (shrimp \& crab) studied revealed the presence of spores of Microsporidia \& oocysts of Cryptosporidia and Cyclospora and. This can be explained by the increased pollution of surface water with these protozoa. These pathogens can enter the food chain and infect fish and man. A similar observation was reported in a project done on public water supplies in Alexandria. It was proved that the highest prevalence of polluting protozoa was in summer(22).

Microsporidia were reported in many aquatic animals, invertebrates and fish(23). Their role as emerging pathogens is being increasingly recognized(13). They are generally transmitted from man to man by direct contact, and can survive in water and food. Recently they have been found in surface water used for drinking(24). Microsporidia was the most frequently encountered parasite in the present work. Spores were isolated from the intestine of both shrimp \& crab. The cause of high prevalence of Microsporidia may be due to the stability of their spores in environment and they remain infective for days to weeks outside their hosts ${ }^{(13)}$. Li et al., (2003)(25) found spores of different Encephalitozoon spp. in water which varied in longevity and temperature tolerance.

Several reports proved the presence of Microsporidia species in crustaceans and bivalves. In Alexandria, parasitological and histopathological studies using light and transmission electron microscopy clarified that crab and bivalve Microsporidia showed common features with those isolated from human stool samples ${ }^{(14)}$.

Another study carried out in Alexandria on bivalves demonstrated Microsporidia in the muscles of shellfish Calatura pruneri (Gandofli) and Donax trunculus (Om el Kholol)(15). 
The parasite's morphology in modified trichrome stained smears, as described by author, was similar to that encountered in present study, where spores appeared small; average size 1 to $2.5 \mu$ in size with a bright pink wall with clear polar or central non staining zones, giving appearance of bands. This was also coinciding with morphological features described by Markell et al., (2006)(26).

Other studies identified different spp. of fish-infecting Microsporidia based on molecular methods. These spp. can inhabit both intestinal epithelium or flesh(27-29). In their ultrastructural diversity, the spores display a voluminous posterior vacuole, which of course is feature proper to most Microsporidia infecting aquatic hosts ${ }^{(16)}$.

Farm animals and humans may be the major sources of Cryptosporidia oocysts contamination in surface water. Furthermore, in Egypt sewage is subjected to minimal treatment and is discharged into rivers and lakes. Hence, there is a risk of contamination with pathogenic protozoa(30). In a study in Ireland, Cryptosporidia was detected in both river waters and in marine mussels(31). Graczyk et al., (1996) suggested that an isolate of Cryptosporidium parvum has established infections in fish, amphibians and reptiles. However, the authors demonstrated the absence of tissue stages of Cryptosporidium parvum in experimentally infected fish, in spite of their presence in their stool from one to 21 days post infection. They concluded that Cryptosporidium parvum was not heterologously transmitted to lower vertebrates, but under certain circumstances, if fish ingested Cryptosporidium parvum infected prey, they can disseminate the oocysts in environment ${ }^{(32)}$. Further molecular studies using phylogenetic analysis would help to elucidate the definitive taxonomic position of genus.

Cyclospora cayetanensis is an emerging 
coccidian pathogen known in animals since

a long time, but recognized in humans in last 2 decades. Transmission occurs mainly by oro-faecal route, and /or by consumption of contaminated water and food(33). Cyclospora cayetanensis was accused of causing many food-borne outbreaks, where food was mainly contaminated by inadequately treated water used for irrigation(24).

In the present study, Cyclospora cayetanensis was the least parasite encountered in both shrimp \& crab. This may be because of its low prevalence in aquatic environment or when excreted in environment it needs several days for sporulation to be infective. A study investigating water sources for pathogenic protozoa reported that the prevalence of cyclospora was only $0.24 \%(30)$. However, cyclospora oocysts were found in bivalves in Alexandria(15). Graczyk et al., (1998) suggested that Cyclospora cayetanensis Alexandria is a public health problem which affects the health of population, not only by oocysts recovered from shellfish in contaminated water can be used as biological indicators for water pollution ${ }^{(34)}$. Although protozoan parasites identified in present study were detected in the intestine of fish, yet this does not diminish their medical importance as a source of infection. Man can be infected by eating undercooked whole small fish that is preferably eaten grilled by Egyptians especially shrimp \& crab where their intestine almost always eaten and can't be avoided. Fish handling, cleaning and preparation can also be hazardous.

It was found that samples brought from El-Halaka and Cleopatara markets were the least infested with emerging protozoa under search this may be due to newly caught fish at $\mathrm{El}$ - Halaka market.

Infective stages of detected parasites may also be excreted by fish under search in their water environment and thus increasing its pollution. Sewage disposal in 
contamination of drinking water, but also

by ruining fish and other sea food highly consumed by people. Thus adequate treatment and proper sewage disposal are top priorities to decrease incidence of parasitic infections among human.

It has been recommended to perform underground water treatment as a prophylaxis against microsporidial contamination before use in culture of crustaceans $^{(33)}$. Regular sampling of aquacultures would be of value to ensure the absence of parasitic

contamination.Identification of spp. of protozoan parasites detected in fish under molecular basis to compare with spp. that infect man is fundamental objective for ongoing research.

These results confirm that, man can be infected by eating undercooked (grilled) crustaceans. Fish handling, cleaning \& preparation can also be hazardous.

Table (1): Comparison of Microsporidia detected by QHG and kinyoun's acid fast in shrimps and crabs

\begin{tabular}{|c|c|c|c|}
\hline & Shrimp & Crab & $Z(p)$ \\
\hline \multicolumn{4}{|l|}{ QH } \\
\hline Range & $1.00-15.00$ & $10.00-70.00$ & \multirow{3}{*}{$6.401^{*}(<0.001)$} \\
\hline Mean \pm SE & $6.47 \pm 0.73$ & $28.47 \pm 3.02$ & \\
\hline Median & 5.00 & 20.00 & \\
\hline \multicolumn{4}{|c|}{ Kinyoun's acid fast } \\
\hline Range & $5.00-30.00$ & $5.00-90.00$ & \multirow{3}{*}{$1.786(0.074)$} \\
\hline Mean \pm SE & $14.97 \pm 1.38$ & $27.67 \pm 4.62$ & \\
\hline Median & 12.00 & 20.00 & \\
\hline Z1 (p) & $4.821^{*}(<0.001)$ & $1.531(0.126)$ & \\
\hline
\end{tabular}

$Z: Z$ for Mann Whitney test between shrimp and crab

$Z_{1}: Z$ for Mann Whitney test between $\mathrm{QH}$ and kinyoun's acid fast

* : Statistically significant at $p \leq 0.05$ 
Table (2): Comparison of Cryptosporidia detected by QHG and kinyoun's acid fast in shrimp and crab

\begin{tabular}{|c|c|c|c|}
\hline & Shrimp & Crab & $Z(p)$ \\
\hline \multicolumn{4}{|l|}{ QH } \\
\hline Range & $0.00-3.00$ & $0.00-2.00$ & \multirow{3}{*}{$1.358(0.174)$} \\
\hline Mean \pm SE & $0.53 \pm 0.16$ & $0.73 \pm 0.14$ & \\
\hline Median & 0.00 & 1.00 & \\
\hline \multicolumn{4}{|c|}{ Kinyoun's acid fast } \\
\hline Range & $0.00-10.00$ & $0.00-3.00$ & \multirow{3}{*}{$0.646(0.519)$} \\
\hline Mean \pm SE & $2.00 \pm 0.46$ & $1.60 \pm 0.18$ & \\
\hline Median & 1.00 & 2.00 & \\
\hline $\mathrm{Z1}(\mathrm{p})$ & $3.543^{*}(<0.001)$ & $3.367^{*}(0.001)$ & \\
\hline
\end{tabular}

$Z: Z$ for Mann Whitney test between shrimp and crab

$Z_{1}: Z$ for Mann Whitney test between QH and kinyoun's acid fast

* : Statistically significant at $p \leq 0.05$

Table (3): Comparison of Cyclospora detected by QHG and kinyoun's acid fast in shrimp and crab

\begin{tabular}{|l|c|c|l|}
\hline & Shrimp & Crab & $\mathbf{Z}(\mathbf{p})$ \\
\hline QH & & & \\
\hline Range & $0.00-3.00$ & $0.00-1.00$ & \\
\hline Mean \pm SE & $0.80 \pm 0.21$ & $0.33 \pm 0.09$ & $1.209(0.227)$ \\
\hline Median & 0.00 & 0.00 & \\
\hline Kinyoun's acid fast & & & \\
\hline Range & $0.00-1.00$ & $0.00-3.00$ & \\
\hline Mean \pm SE & $0.40 \pm 0.09$ & $0.47 \pm 0.15$ & $0.316(0.752)$ \\
\hline Median & 0.00 & 0.00 & \\
\hline $\mathbf{Z}_{1}(\mathbf{p})$ & $0.812(0.417)$ & $0.180(0.857)$ & \\
\hline
\end{tabular}

$Z: Z$ for Mann Whitney test between shrimp and crab

$Z_{1}: Z$ for Mann Whitney test between QH and kinyoun's acid fast 
Table (4): Percentages of emerging protozoa in shrimp using two staining techniques QHG and KAF.

\begin{tabular}{|c|c|c|c|c|c|c|}
\hline & \multicolumn{2}{|c|}{ Microsporidia } & \multicolumn{2}{|c|}{ Cryptosporidia } & \multicolumn{2}{|c|}{ Cyclospora } \\
\hline & No. & $\%$ & No. & $\%$ & No. & $\%$ \\
\hline \multicolumn{7}{|l|}{ QH } \\
\hline$-\mathrm{ve}$ & 0 & 0 & 20 & 66.7 & 18 & 60.0 \\
\hline +ve & 30 & 100 & 10 & 33.3 & 12 & 40.0 \\
\hline \multicolumn{7}{|c|}{ Kinyoun's acid fast } \\
\hline$-\mathrm{ve}$ & 0 & 0 & 6 & 20.0 & 18 & 60.0 \\
\hline$+\mathrm{ve}$ & 30 & 100 & 24 & 80.0 & 12 & 40.0 \\
\hline$\chi^{2}(p)$ & \multicolumn{2}{|c|}{-} & \multicolumn{2}{|c|}{$13.303^{*}(<0.001)$} & \multicolumn{2}{|c|}{$0.000(1.000)$} \\
\hline
\end{tabular}

$\chi^{2}$ : Chi square test

${ }^{*}$ : Statistically significant at $p \leq 0.05$

Table (5): Percentages of emerging protozoa in crab using different staining techniques

\begin{tabular}{|c|c|c|c|c|c|c|}
\hline & \multicolumn{2}{|c|}{ Microsporidia } & \multicolumn{2}{|c|}{ Cryptosporidia } & \multicolumn{2}{|c|}{ Cyclospora } \\
\hline & No. & $\%$ & No. & $\%$ & No. & $\%$ \\
\hline \multicolumn{7}{|l|}{ QH } \\
\hline$-v e$ & 0 & 0 & 14 & 46.7 & 20 & 66.7 \\
\hline$+\mathrm{ve}$ & 30 & 100 & 16 & 53.3 & 10 & 33.3 \\
\hline \multicolumn{7}{|c|}{ Kinyoun's acid fast } \\
\hline$-\mathrm{ve}$ & 0 & 0 & 4 & 13.3 & 20 & 66.7 \\
\hline$+v e$ & 30 & 100 & 26 & 86.7 & 10 & 33.3 \\
\hline Test of sig. & & & \multicolumn{2}{|c|}{$\mathrm{FEp}=0.010^{*}$} & \multicolumn{2}{|c|}{$\begin{array}{c}\chi 2=0.000 \\
p=1.000\end{array}$} \\
\hline
\end{tabular}

$\chi^{2}$ : Chi square test

FEp: $p$ value for Fisher Exact test

${ }^{*}$ : Statistically significant at $p \leq 0.05$ 
Table (6): Comparison between different markets in Alexandria as regard intensity of microsporidial infection in shrimp and crab

\begin{tabular}{|c|c|c|c|c|c|}
\hline & & Halaka & Cleop. & Shidia & Hadra \\
\hline \multirow{14}{*}{ I } & Shrimp & & & & \\
\hline & Range & $3.00-5.00$ & $2.00-8.00$ & $1.00-13.00$ & $8.00-15.00$ \\
\hline & Mean \pm SE & $4.33 \pm 0.42$ & $4.50 \pm 0.87$ & $6.25 \pm 1.76$ & $10.25 \pm 1.08$ \\
\hline & $\chi^{2}(p)$ & \multicolumn{4}{|c|}{$11.116^{*}(0.011)$} \\
\hline & Z1 (p) & & $0.273(0.785)$ & $0.265(0.791)$ & $3.180^{*}(0.001)$ \\
\hline & $\mathbf{Z 2}(p)$ & & & $0.428(0.669)$ & $3.031 *(0.002)$ \\
\hline & Z3 (p) & & & & $1.732(0.083)$ \\
\hline & Crap & & & & \\
\hline & Range & $10.00-20.00$ & $12.00-15.00$ & $20.00-45.00$ & $20.0-70.00$ \\
\hline & Mean \pm SE & $16.25 \pm 1.57$ & $28.00 \pm 5.37$ & $28.75 \pm 3.87$ & $45.00 \pm 9.13$ \\
\hline & $\chi^{2}(\mathrm{p})$ & \multicolumn{4}{|c|}{$10.406^{*}(0.015)$} \\
\hline & Z1 (p) & & $1.732(0.083)$ & $2.701^{*}(0.007)$ & $2.700^{*}(0.007)$ \\
\hline & $Z 2(p)$ & & & $0.218(0.828)$ & $1.313(0.189)$ \\
\hline & $Z 3(p)$ & & & & $1.363(0.173)$ \\
\hline \multirow{10}{*}{ 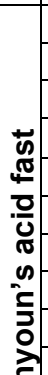 } & Shrimp & & & & \\
\hline & Range & $5.00-15.00$ & $10.00-12.00$ & $5.00-30.00$ & $15.00-30.00$ \\
\hline & Mean \pm SE & $10.67 \pm 1.87$ & $11.25 \pm 0.31$ & $15.00 \pm 3.54$ & $21.25 \pm 2.06$ \\
\hline & $\chi^{2}(p)$ & \multicolumn{4}{|c|}{$11.724^{*}(0.008)$} \\
\hline & Z1 (p) & & $0.540(0.589)$ & $0.530(0.596)$ & $2.915^{\star}(0.004)$ \\
\hline & $\mathrm{Z2}(\mathrm{p})$ & & & $0.214(0.831)$ & $3.422^{*}(0.001)$ \\
\hline & $\mathrm{Z3}(\mathrm{p})$ & & & & $1.721(0.085)$ \\
\hline & Crap & & & & \\
\hline & Range & $5.00-20.00$ & $10.00-20.00$ & $20.00-30.00$ & $65.00-90.00$ \\
\hline & Mean \pm SE & $11.25 \pm 2.06$ & $13.75 \pm 1.57$ & $22.50 \pm 1.64$ & $75.00 \pm 4.83$ \\
\hline \multirow[t]{4}{*}{$\underline{\mathbf{z}}$} & $\chi^{2}(p)$ & \multicolumn{4}{|c|}{$22.051^{*}(<0.001)$} \\
\hline & $\mathrm{Z1}(\mathrm{p})$ & & $1.133(0.257)$ & $2.946 *(0.003)$ & $3.151^{*}(0.002)$ \\
\hline & $Z 2(p)$ & & & $2.946^{*}(0.003)$ & $3.151^{*}(0.002)$ \\
\hline & $Z 3(p)$ & & & & $3.240^{*}(0.001)$ \\
\hline
\end{tabular}

$\chi$ : Chi square for Kruskal Wallis test between the different markets

$Z_{1}: Z$ for Mann Whitney test between Halaka and other markets

$Z_{2}: Z$ for Mann Whitney test between Cleop. With Shidia and Hadra

$Z_{3}: Z$ for Mann Whitney test between Shidia and Hadra 


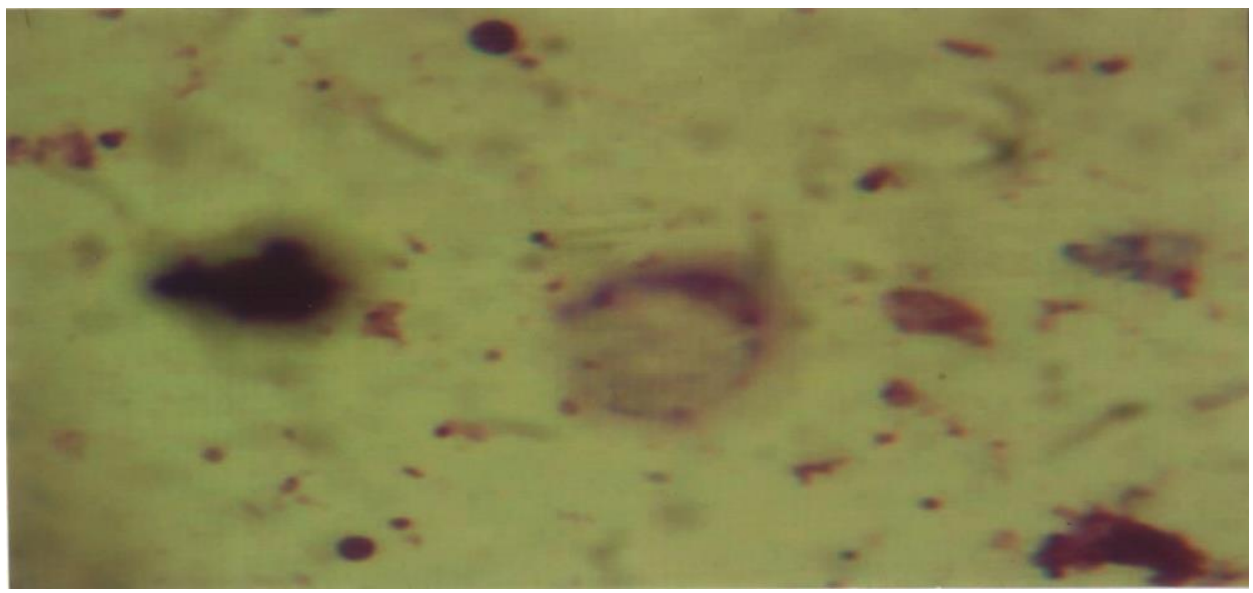

Figure (1): Microsporidia, Cryptosporidia, Cyclospora, and Blastocystis hominis in crab using KAF stain.

\section{REFERENCES}

1. Mattson S. Working toward cultural competence working. A WHONN life lines. 2000; 4(4): 41-3.

2. Meyer's BJ. Nematodes transmitted to man by fish \& aquatic mammals- J wildlife Dis 1970; 6: 266-71.

3. WWW.fao.org/events/FAO corporate document respository: Title: Assurance of sea food quality.

4. Wasson K. Mammalian microsporidiosis. Vet Pathol 2000; 37(2): 113-28.

5. Garcia LS. Intestinal protozoa (Coccidia and Microsporidia) and Algae. In: Diagnostic Medical parasitology. $5^{\text {th }}$ ed. American Society for Microbiology, ASM Press, Washington 2007; 57-97.

6. Fayer R, Santin M, Palmer R. Comparison of microscopy \& PCR for detection of $3 \mathrm{spp}$ of Encephalitozoon in feces of experimentally infected chickens. J Eukaryot Microbiol 2003 a;

50: 572-3.

7. Fayer R, Santin M, Trout JM. First detection of Microsporidia in dairy calves in North American. Parasitol Res 2003 C; 90: 383-6.

8. Kahler AM, Jaenette A, Enriquez T. Human pathogenic Micrsporidia detection in agricultural samples: method development \& assessment. Parasitol Res. 2007; 100: 529-38.

9. Xiao L, Fayer R, Ryan U, Upton SJ. Cryptosporidium Taxonomy: recent advances and implications for public health. Clin Microbiol Rev 2004; 17(1): 72-97.

10. Laberge I, Griffiths MW. Prevalence, detection and control of Cryptosporidium parvum in food. Int $\mathrm{J}$ Food Microbiol 1996; 31: 1-26.

11. Garcia LS. Unusual parasitic infections. In: Diagnostic Medical Parasitology $5^{\text {th }}$ ed. American Society 
for Microbiology, ASM press, Washington 2007; 478-505.

12. Chai JY, Murrel KD, Lympery AJ. Fish-borne parasitic zoonosis: status and issues. Int $\mathrm{J}$ Parasitol 2005; 35: 1233-54.

13. Slif JR, Smith HV, Rose JB. Emerging parasite zoonoses associated $\mathrm{C}$ water \& food. Int J Parasitol 2000; 30(1213): 1379-93.

14. Awadallah HN, Khalifa AM, Sadaka $\mathrm{HH}$, Helal SM. A comparison between human, crustacean and bivalve isolates of Microsporidia. J Egypt Soc Parasitol 2000; 30(3): 709-16.

15. Negm AY. Human pathogenic protozoa in bivalves collected from local markets in Alexandria. J Egypt Soc Parasitol 2008; 33(3): 991-8.

16. Lom J, Nilsen F. Fish Microsporidia: Fine structural diversity and phylogeny. Int J Parasitol 2003; 33: 107-27.

17. Rouse W. Crabs, their taxonomy, anatomy, physiology \& geographic distribution 2007 available at marinelife suita 101.com/article. Cfm/crabs.

18. Ryan MK. Anatomy of shrimp. 1997 www.shrimpcrabsandcryfish. co/uk/anatomy.html.

19. Weber R, Bryan RT, Owen RL, Wilcox CM, Gorelkin L, Visvesvara GS. Improved light microscopical detection of Microsporidia spores in stool and duodenal aspirates. $\mathrm{N}$ Engl $\mathrm{J}$ Med 1992; 326: 161-6.

20. Kokoskin E, Gyorkos TW, Camus A, Cedilottl 'L, Purtill T, Ward B. Modified technique for efficient detection of Microsporidia. J Clin Microbiol 1994; 32(4): 1075-974.

21. Garcia LS and Bruckner D A. Techniques for recovery and identification of Cryptosporidium oocysts from stool specimens. J clin Microbiol 1983; 18: 185-90.

22. WHO project TSA 99153 and Parasitol. Dep. Fac., Med. 2000:
Parasitological agents in public water supplies in Alexandria.

23. Lujan HD, Conrad JT, Clark CG, Touz MC, Delbac F, Vivares CP, et al TE. Detection of Microsporidia Sporespecific antigen by monoclonal antibodies. Hybridoma 1998; 17 (3): 237-43.

24. Mota P, Rauch CA, Edberg SC. MicroSporidia and Cyclospora: Epidemiology and assessment of risk from the environment. Crit Rev Microbiol 2000; 26(2): 69-90.

25. Li Z, Palmer R, Trout JM, Fayer R. Infectivity of Micrsporidia spores stored in water at environmental temperatures. J Parsitol 2003; 89(1): 185-9.

26. Markell E, and Voge M. Lumen dwelling protozoa. In: Medical Parasitology $9^{\text {th }}$ ed. Elsevier's Health Sciences (EHS), Philadelphia 2006; 74-6.

27. Nelsen F, Endersen C, Hordvik I. Molecular phylogeny of Microsporidia with particular reference to species that infect fish. J Eukaryot Microbiol 1998; 45(5): 535-43.

28. Nilsen F. Small subunit ribosomal DNA phylogeny of Microsporidia with particular reference to the genera that infect fish. J Parasitol 2000; 86(1): 128-33.

29. Whipps CM, Kent ML. Polymerase chain reaction detection of Pseudeloma neurophilia, a common Microsporidia of zebra fish (Danio rerio) rared in research laboratories. $\mathrm{J}$ Am Assoc Lab Anim Sci 2006; 45(1): 36-9.

30. El Shazly AM, El Sheikha HM, Soltan DM, Mohamed KA, Morsy JA. Protozoal pollution of surface water sources in Dakahlia governorate, Egypt. J Egypt Soc Parasitol 2007; 37(1): 51-64.

31. Chalmers RM, Sturdee AP, Mellors P, Nicholson V, Lowlor F, and Timpson 
V. Cryptosporidium parvum in environmental samples in the silgo area, republic of Ireland: A preliminary report. Lett Appl Microbiol 1997; 25(5): 380-4.

32. Graczyk TK, Fayer R, Cranfield MR. Cryptosporidium parvum is not transmissible to fish, amphibians, or reptiles. J Parasitol 1996; 82(5): 74851.

33. Bouree $P$, Lancon A, Bisaro F, Bonnot G. Six human cyclosporiasis: with general review. J Egypt Soc Parasitol 2007; 37(2): 349-60
34. Graczyk TK, Ortega YR, Conn DB. Recovery of water-borne oocysts of Cyclospora cayetanensis by Asian fresh water clams (corbicula fluminea). Am J Trop Med Hyg 1998; 59(6): 92832.

35. Purivirojkul W, Khidprasert S. First report of microsporidiosis in fairy shrimp Branchinella thailandensis (Sanoamuang, Saengphan and Murugan, 2002) 24 June 2008 available from: http://www.elsevier.com/locate/aquaon line 
